the other two medical schools for some time, but for the past 15 years psychiatrists from Addis Ababa are the ones who have done most of the teaching in those institutions.

Since there was no postgraduate training programme for psychiatry in Ethiopia, doctors had to go abroad to do their training. Currently there are five trainees abroad two in the UK, two in South Africa and one in Russia; they are expected to return to Ethio pia within 1-2 years to practise psychiatry.

In January 2003 the D epartment of Psychiatry, Faculty External funding sources and collaboration with universities abroad have contributed greatly to mental health research in Ethiopia. of Medicine, Addis Ababa U niversity, started a 3-year postgraduate training programme with a first intake of seven doctors. The department has only three academic staff, all of whom are general adult psychiatrists: one Associate Professor and two Assistant Professors. The department has been able to solicit assistance for the teaching of its postgraduate students from universities and individuals abroad. The Department of Psychiatry at the U niversity of Toronto, Canada, has committed itself to assisting the programme by sending two teachers for three 1-month blocks every year for 3 years. This is part of the $U$ niversity of Toronto's commitment to developing international partnerships for collaborative education and research. In addition to the Toronto-based faculty teaching in Ethiopia, psychiatrists from the University of Addis Ababa will visit Toronto to present research papers and to teach. The programme is also an opportunity to share expertise in mental health service delivery, research and education, and advocacy for mental health issues in both countries.

Volunteers from The N etherlands, England, Australia, Sweden and the USA also have contributed greatly in the postgraduate training programme, which is proving a success. More institutional collaborations are being sought to strengthen the programme until the department becomes self-sufficient.

\section{Research}

Despite the facts that the number of psychiatrists in Ethiopia has always been minimal, the resources are limited and the infrastructure is poorly developed, quite a few research papers have been published in international and local journals since the 1960s. Particularly over the past 10 years, mental health research in the country has changed significantly. Epidemiological studies in different population groups such as children, adults, islanders, semi-nomads, displaced people and women have been conducted in towns and rural settings. Some of these studies are ongoing. For example, a cohort of patients with schizo phrenia and bipolar disorder is being followed in Butajira D istrict, a rural setting, to describe the course and outcome of these disorders, which is one of the few such studies in the world in these settings (Kebede et al, 2003). A good number of publications have appeared in international and local journals from these studies. External funding sources and collaboration with universities abroad have contributed greatly to mental health research in Ethiopia.

\section{References}

Alem, A. (2000) Human rights and psychiatric care in Africa with particular reference to the Ethiopian situation. Acta Psychiatrica Scandinavica Supplementum, 399, 93-96.

Central Statistical Authority (1995) Statistical Abstract of Ethiopia. Addis Ababa: CSA.

Central Statistical Authority (2000a) Statistical Abstract of Ethiopia. Addis Ababa: CSA.

Central Statistical Authority (2000b) Demographic and Health Survey of Ethiopia. Addis Ababa: CSA.

Central Statistical Authority (2002) Statistical Abstract of Ethiopia. Addis Ababa: CSA.

Hailemariam, A. \& Kloos, H. (1993) Population. In The Ecology of $\mathrm{H}$ ealth and Disease in Ethiopia (eds H. Kloos \& Z. A. Zein), pp. 47-66. Boulder, CO: Westview Press.

Kebede, D., Alem, A., Shibre, T., et al (2003) O nset and clinical course of schizophrenia in Butajira, Ethiopia. International Journal of Social Psychiatry and Psychiatric Epidemiology, 38, 625-631.

Ministry of Health (2002) Health and Health Related Indicators. Addis Ababa: Ministry of Health.

Population Reference Bureau (2000) World Population Data Sheet. Washington, DC: PRB.

Transitional Government of Ethiopia (1993) Health Policy of the Transitional Government of Ethiopia. Addis Ababa: TGE.

World Bank (1994) Better Health in Africa: Experience and Lessons Learned. Washington, DC: World Bank.

World Health $O$ rganization (2001) Atlas: Country Profile of M ental Health Resources. Geneva: WHO.

\title{
Mental health services in Israel
}

\section{Itzhak Levav ${ }^{1}$ and Alexander Grinshpoon ${ }^{2}$}

\begin{abstract}
${ }^{1}$ Adviser, Mental Health Services, Ministry of Health, Jerusalem, Israel, email Itzhak.Levav@moh.health.gov.il 2Director, Mental Health Services, Ministry of Health, Jerusalem, Israel
\end{abstract}

\author{
srael is a multicultural society in a state of \\ permanent change. The population, of about 6.5 \\ million, comprises the following religious groupings: \\ Jews (77.5\%), Muslims (15.3\%), Christians (2.1\%), \\ Druzes $(1.7 \%)$ and others $(3.4 \%)$. The organisation \\ of and the approaches used by the country's health \\ services have been determined by this socio-
}

cultural plurality, and also by a continuous influx of immigrants (among whom, 882600 and 44200 arrived from countries of the former USSR and Ethiopia, respectively, between 1990 and 2001), as well as by the precarious security situation (the country has seen several wars with its neighbours in addition to the long-standing conflict with 
the Palestinians). The patterns of care of the population reflect both Western psychiatry and traditional systems. Because of such complexity, the present brief overview is necessarily selective.

\section{Health indicators}

The description of mental health services that follows will be better understood against a background of selected public health indicators and socio-demographic variables. Mean life expectancy in the year 2000 was 76.7 years for men and 80.9 for women. The infant mortality rate was 5.1 per 1000 live births in the year 2001. The coverage for immunisation for poliomyelitis reached $93 \%$ during the first year of life (1998 figure). The chief causes of mortality are the chronic disorders, an area of health that calls for closer linkage with the mental health professions. With regard to age, $28.5 \%$ of the population are under 15 years and $9.8 \%$ are 65 years old or more. The median time spent in education for people aged 15 and over was 12.3 years by the year 2000 . All these figures refer to the combined Israeli population; however, there are some notable differences between specific population groups (Central Bureau of Statistics, 2002).

\section{National health insurance}

By law, all residents are insured for health care and contribute to a national fund according to income. Most of the population is served by one of the four health maintenance organisations, the largest of which was established in the pre-State years (before 1948) by the labour unions.

Importantly, the law that established this health system did not include either psychiatric care or geriatric and nursing services. In 2002, the government decided to transfer all responsibility for mental health care (see below) to the health maintenance organisations; implementation of this decision is expected in 2005.

Care provided by a general practitioner is free. A visit to a specialist (other than a psychiatrist) carries a nominal fee (less than US\$5). Visits to a psychiatric clinic, care in a psychiatric hospital or hostel, and certain specified drugs are free of charge. Preventive maternal and child health services are provided free by the municipalities and by the Ministry of $\mathrm{H}$ ealth.

\section{Policy principles guiding the provision of mental health care}

Israel has not yet developed a national mental health plan, but the first steps are being taken and the political will exists to formulate one. 0 nce adopted, the plan will be based on the following policy objectives, which are endorsed by almost all stakeholders:

o to promote the mental health of the population

o to integrate mental health care within the general health system

O to ensure equity of access to services in all parts of the country

$O$ to provide high-quality evidence-based and costeffective care to persons with mental disorders
O to promote the psychosocial rehabilitation of persons with mental disability

o to strengthen and expand community-based care and reduce both hospital admission rates and length of stay

0 to ensure the availability of emergency and crisis services, specially in security-related situations.

\section{The organisation of mental health care}

The government is responsible for the overall planning, budgeting and monitoring of the mental health care provided to all the population. Two multi-sectoral national advisory councils, one on mental health and the other on community-based mental health rehabilitation, assist the government in this.

The national fight against addictions, including health promotion and prevention activities, is the responsibility of an autonomous council. The services, such as methadone supply, how ever, are the responsibility of the Ministry of $H$ ealth, in association with the welfare system.

The Ministry of $\mathrm{H}$ ealth allocates $5.9 \%$ of its budget to mental health services (2002 figure). This is not all the budget available for public mental health care, since this percentage does not include sums from other public-sector organisations. As noted above, curative care is provided by the government, although some services are offered by the health maintenance organisations. The responsibility for psychosocial rehabilitation services is shared with the welfare services and, especially, with the $\mathrm{N}$ ational Insurance Institute (see section on legislation, below).

Any inhabitant can freely access any mental health curative service (Feinson et al, 1997). Although referral by a general practitioner is preferable, any resident can attend mental health services directly, without such a referral. The country has 114 clinics and day-care centres, 12 psychiatric wards in general hospitals and 20 mental hospitals.

Since the early 1950s, Israel has run a psychiatric case register. All admissions and discharges are cumulatively entered into a database. of late, this database has incorporated additional sources of information (e.g. clinicoriginated information). The confidentiality of the database is specifically protected by law (D epartment of Information and Evaluation, 2002).

Table 1 highlights some statistics relating to in-patient care in Israel. The rates of hospital admission per

Table 1. In-patient psychiatric services, 2001

Beds (number per 1000 persons aged 15 and above) 1.17

Annual rate of first admission, per 1000 persons aged 15 and above Total

Jews

0.99

M uslim Arabs

0.70

Others

0.34

2.96

Annual rate of readmissions per 1000 persons aged 15 and above

Annual admission rate per 1000 persons aged 15 and above

to in-patient and hospital-based day care

Men

3.4

Women

2.3

Average length of hospital stay (days)

131

Proportion of all admissions that are voluntary 
1000 are lowest for Muslims (men 2.50, women 1.19), intermediate for C hristian Arabs (2.48 and 1.69, respectively) and highest for Jews (3.49 and 2.50, respectively). Similarly to most countries, $51.8 \%$ of admissions are for schizophrenia or delusional disorders. Five per cent of psychiatric beds are in general hospitals. The number of beds has fallen over time.

\section{Consumer and family organisations}

These organisations are highly visible and active in both advocacy and mutual support. (A special issue of the Israel Journal of Psychiatry, vol. 39, no. 3, 2002, was wholly devoted to the consumers of mental health services.) They have representation on the national councils and have a strong voice in the efforts leading to the transfer of mental health care to the health maintenance organisations. The Ministry of $\mathrm{H}$ ealth recognises their important role in the humanisation and democratisation of mental health care by contributing to their support. These organisations were consulted in the process of drafting the laws alluded to below and their representatives take part in the qualitycontrol activities that have recently been initiated.

In addition, several non-government organisations are active in mental health care, such as ERAN, which offers telephone first-aid assistance nationally, and another that provides initial guidance to foreign workers.

\section{Legislation on psychosocial rehabilitation}

Perhaps the single most important piece of legislation that facilitates the ongoing - but slow - process of psychiatric reform is that adopted in 2000. This is the CommunityBased Rehabilitation of the Mentally D isabled Act, whereby all consumers whose degree of mental disability reaches $40 \%$, as established by the $N$ ational Insurance Institute, are fully entitled to receive a set of rehabilitation services in the community. This law has enabled the mental hospitals to discharge people who would otherwise remain merely for custodial reasons and to promote their social reintegration. Funds have thus become available to contract out to private and social enterprises running hostels with different levels of supervisory services for their clients. To avoid recreating the atmosphere of mental institutions, these hostels are periodically inspected by staff from the Ministry of $\mathrm{H}$ ealth.

The range of rehabilitation services is wide: they include dental care, for example - an item often neglected in psychiatric health plans- and supported education. With regard to the latter, special efforts are being made to help consumers to complete their educational cycle within the regular system of education for adults.

\section{Health services and the security situation}

The unstable security situation has led the country to devote considerable resources (in services, research and teaching) to help the civilian population overcome the stress resulting from both open warfare and acts of terrorism. This section alludes to the $1991 \mathrm{GulfW}$ War, when areas of the country were subjected to missile attack by Saddam H ussein's Iraq, and to the current second Intifada, which began in 0 ctober 2000.

In the GulfWar, studies covered a number of health issues among adults, such as mortality (the early elevated cardiovascular mortality rate that was found was presumably linked to the use of gas masks and extended stays in sealed rooms - Kark et al, 1995); self-appraisal of physical health (worsened health status); health behaviour (increased smoking, diminished physical activity, changed eating habits); and psychological distress (higher in the exposed areas) (N akar et al, 1996; Soskolne et al, 1996). 0 ther studies explored reactions in children (Laor et al, 1996) and among the elderly (Solomon \& Prager, 1992), and acute stress in evacuees (Solomon et al, 1993).

Soskolne et al (1996), in addition to the measures noted above, enquired into the use of tranquillisers and the use of services. They fo und higher use of tranquillisers compared with the preceding month but no differences in service utilisation.

$\mathrm{N}$ akar et al (1996) compared the 2-week consulting load in a family practice of an area that was highly exposed to SCUD missile attack with the equivalent period during the previous year. The authors reported that the total rate of visits was cut by half, but with a relative and absolute increase in psychological consultations and a decrease in consultations for infectious and respiratory conditions. Apparently, worries about the attacks led to a reduction in consultations for trivial disorders, but to an increase in the anxiety level of the population.

D uring the second Intifada, the Ministry of $\mathrm{H}$ ealth and several non-governmental organisations have established mental health activities that are provided as early as possible in the emergency rooms and wards of general hospitals that treat casualties. The Ministry has trained several teams of eight mental health specialists, who are attached to a general hospital. Half of them are trained to care for children and adolescents, and half for adults. Immediately following an attack (or other disaster), they are expected to report to their hospital. Their task is to examine all persons who are lightly injured and those suffering from a stress reaction. Following first-aid treatment, everyone is transferred to another area near the emergency room for individual and group intervention. The intervention includes an explanation about the nature of psycho-trauma, the provision of emotional support and the giving of information about psychological and social security assistance. This information is offered in five languages - H ebrew, English, Russian, Arabic and Amharic. An additional role of the mental health team is to provide emotional support to doctors and nurses who are involved in the care of the wounded.

H ospital social workers are responsible for meeting the family members and friends of the injured, and helping them to locate the casualties, assist with their grief, and accompany the family members to the hospital morgue to identify victims.

The Ministry of Health's system for emergency intervention and treatment with regard to psychological trauma 
also includes activities that take place at the community level. Trained personnel in out-patient clinics are entrusted with the care of persons affected by acute stress disorders or post-traumatic stress disorder. At the time of a national emergency, these out-patient clinics are open 24 hours a day.

\section{Research}

Much mental health research has been and is being conducted both in the universities and in the services. $N$ ational and international funding sources support Israeli research. For the sake of brevity, the main areas of research are briefly summarised below. The studies cited here are merely examples - a national database is available at www.szold.org.il.

\section{Epidemiology}

Studies have been conducted with regard to the mental health of communities both in peace and in war. Currently, the national authorities are conducting household surveys of the young and adults, the latter as part of epidemiological studies in a number of countries, run jointly by the World $\mathrm{H}$ ealth $\mathrm{O}$ rganization and $\mathrm{H}$ arvard U niversity. A large survey exploring emotional distress (common mental disorders) among Arabs and Jews has concluded relatively recently. The fact that many early immigrants were H olocaust survivors provided the substance for studies on the mental health status of first- and second-generation immigrants (Levav, 1998).

\section{Social psychiatry}

The cultural mosaic of Israel has prompted investigators to explore the knowledge, attitudes and practices of different Arab and Jewish groups of the population.

\section{Health services research}

The Ministry of $\mathrm{H}$ ealth supports a relatively large staff, who are entrusted with the responsibility of providing data for planning, monitoring and evaluation. These efforts are buttressed by studies conducted by university staff and students.

\section{Biological psychiatry}

This area, in consonance with the current psychiatric zeitgeist, is flourishing and making significant contributions in a number of respects, particularly with regard to schizophrenic, obsessive and depressive disorders and posttraumatic stress disorder.

\section{Training}

Graduate, postgraduate and in-service education is a vibrant area. The country trains all the range of mental health professionals (clinical psychologists, nurses, etc.). There are 16.4 psychiatrists per 100000 population. The register of the $C$ hild and Adolescent Society numbers about 150 specialists (Apter, 1998). In addition, there are approximately 200 residents in training. To be recognised as a specialist, the resident has to complete four years of postgraduate education in a variety of services and pass two examinations.

\section{Looking back, moving forward}

Throughout the country's history, the mental health services in Israel have had to face the challenge of how to provide care to persons from very different cultural and religious backgrounds - Jewish, Muslim, D ruze and Christian - see Al-Krenawi (1999) and Al-Krenawi \& Graham (1999) with regard to the Arabs, and Bilu \& W itztum (1997) and Greenberg \& W itztum (2001) with regard to different Jewish Israeli groups, who emigrated from 70 or so countries, wherein many had endured severe persecution and the traumatic loss of their significant others, and whose lives since the dawn of the State have been punctuated by war and terrorism.

A judgement on how well the services have performed is beyond the scope of this report. However, it is fair to say that mental health care is increasingly recognised by decision makers and the public as an important link in the chain of efforts that the health system makes towards the health of the nation. Mental health services are free and open to all, and the service users and their families are being sought as natural partners of mental health professionals.

In the field of research, Israel is contributing its share to the global pool of scientific knowledge, as has been noted by Patel (2002).

Admittedly, not all is well. Psychiatric reform, which involves deinstitutionalisation, community-based care and the humanisation of services, is progressing more slowly than is wished by many. Mental hospitals still remain the main axis of care, command an unusual amount of power and authority, and consume most of the mental health budget. A large proportion of their personnel, although less fearful of community-based care than they were, remain ambivalent at best about the psychiatric reform that is leading to the transfer of mental health care to the health maintenance organisations. Despite the free access to care, equity has not been achieved, and the barriers to care for foreign workers, particularly those without papers, have not been lowered. Child and adolescent mental health services and services for the elderly, although available, are probably less than are needed (an ongoing survey will identify needs among the young). A last limitation worth noting is that the services have yet to balance their efforts in care and rehabilitation with health promotion and illness prevention.

In conclusion, the Israeli mental health services are genuinely attempting to upgrade the mental health care for the whole population. To overcome the remaining and still formidable obstacles, both internal and external, to the system, will require, much as in other nations, the support of many stakeholders, and a successful blend of po litical and social will, the application of scientific and technical know-how, the involvement of service users and their families, and the dedication and commitment of mental health workers.

\section{Mental hospitals still remain the main axis of care, command an \\ unusual amount of power and authority, and consume most of the mental health budget.}


Acknowledgement

Bella Ben-Gershon, BA, provided information on the emergency preparedness programme.

\section{References}

Al-Krenawi, A. (1999) Explanation of mental health symptoms by the Bedouin-Arabs of the N egev. International Journal of Social Psychiatry, 45, 56-64.

Al-Krenawi, A. \& Graham, J. R. (1999) Gender and biomedical/ traditional mental health utilization among the Bedouin-Arabs of the N egev. Culture, Medicine and Psychiatry, 23, 219-243.

Apter, A. (1998) Child psychiatry in Israel - towards the millennium. Israel Journal of Psychiatry, 35, 251-252.

Bilu, Y. \& W Witztum, E. (1997) The mental health of Jews inside and outside Israel. In Ethnicity, Immigration, and Psychopathology (eds I. Al-Issa \& M. Tousignant), pp. 235-256. N ew York: Plenum

Central Bureau of Statistics (2002) Statistical Abstract 2001. Jerusalem: G overnment of Israel.

Department of Information and Evaluation (2002) Mental Health in Israel. Statistical Annual 2002. Jerusalem: Ministry of Israel.

Feinson, M. C., Lerner, Y., Levinson, D., et al (1997) Ambulatory mental health treatment under universal coverage: policy insights from Israel. M ilbank Quarterly, 75, 235-260.

Greenberg, D. \& Witztum, E. (2001) Sanity and Sanctity. N ew Haven, CT: Yale University Press.
Kark, J. D., Goldman, S. \& Epstein, L. (1995) Iraqi missile attacks on Israel. The association of mortality with a life-threatening stressor. Journal of the American Medical Association, 273, 1208-1210.

Laor, N., Wolmer, L., Mayes, L. C., et al (1996) Israeli preschoolers under SCUD missile attacks. A developmental perspective on risk-modifying factors. Archives of General Psychiatry, 53, 416-423.

Levav, I. (1998) Individuals under conditions of maximum adversity. In Stress, Adversity and Psychopathology (ed. B. P. Dohrenwend). N ew York: 0 xford U niversity Press.

$\mathrm{N}$ akar, S., Kahan, E., N ir, T., et al (1996) The influence of SCUD missile attacks on the utilization of ambulatory services in a family practice. Medicine, Conflict, and Survival, 12, 149-153.

Patel, V. (2002) Research Environment in Developing Countries: Making It Happen. Cape Town: World Health O rganization.

Solomon, Z. \& Prager, E. (1992) Elderly Holocaust survivors during the Persian Gulf War: a study of psychological distress. American Journal of Psychiatry, 149, 1707-1710.

Solomon, Z., Laor, N., Weiler, D., et al (1993) The psychological impact of the Gulf War: a study of acute stress in Israeli evacuees. Archives of General Psychiatry, 50, 320 321.

Soskolne, V., Baras, M., Palti, H., et al (1996) Exposure to missile attacks: the impact of the Persian Gulf War on physical health behaviors and psychological distress in high and low risk areas in Israel. Social Science and Medicine, 42, 1039-1047.

\title{
Mental health services in Albania
}

\author{
Anastas Suli ${ }^{1}$, Ledia Lazëri² and Livia Nano ${ }^{3}$
}

\begin{abstract}
${ }^{1}$ Head of the Psychiatric Department of the University Hospital Centre, 'Mother Teresa', Tirana, and Chairman of the National Steering Committee for Mental Health

${ }^{2}$ National Professional Officer at the WHO Country Office, Albania, and Coordinator of the Albanian

Development Centre for Mental Health, email ledial@who-albania.org

${ }^{3}$ Psychologist at the Albanian Development Centre for Mental Health
\end{abstract}

The care system remains prey to financial and regulatory rigidity. The system is still highly centralised and lacks a focus on the social welfare of citizens. Decentralisation and open governance within a framework of comprehensive reform are prerequisites for better services.
Ibania, situated in the western Balkans, has an area of $28748 \mathrm{~km}^{2}$ and a population of 3069275 (year 2001), almost one-third of whom are aged 0-14 years. Life expectancy is estimated to be 70.4 years for both sexes (World Health $O$ rganization, 2003a). According to the World Health O rganization's classification, Albania is a country with low child and low adult mortality rates. The nation's total expenditure on health in 2001 amounted to $3.7 \%$ of gross domestic product.

For more than a decade Albania has been undergoing a transitional process of democratisation of its so ciety and decentralisation of its systems, including systems of care in general. H ow ever, its relatively recent totalitarian past had created a culture of lack of community initiative, participation and decision-making, and the care system remains prey to financial and regulatory rigidity. The system is still highly centralised and lacks a focus on the social welfare of citizens. Decentralisation and open governance within a framew ork of comprehensive reform are prerequisites for better services. Furthermore, any intervention to improve the health system will need to take into account the fact that Albania is not a rich country and health is not the top priority when it comes to the allocation of national resources.

\section{Education in psychiatry}

Formal psychiatric education is provided by the only university department of psychiatry in the country; it is part of the Faculty of Medicine of the U niversity of Tirana. Education in psychiatry has had to be transformed in order for it to meet international standards. W hile psychiatry constitutes $1.4 \%$ of the overall training hours in the university curriculum for medical doctors, in 1994 postgraduate psychiatric education was extended from 9 months of internship to 4 years of residency in the university clinic.

Residents annually discuss their training plan with their supervisors. They attend to and follow clinical cases in their charge. The professional qualification for psychiatrists involves several yearly examinations across the entire residency period, and one final examination (oral and written). While the curriculum offers satisfactory training in biological psychiatry, it is difficult to train young residents properly in the psychosocial aspects of practice, as there are few supervisors with sufficient experience and 